\title{
INSUSTENTABILIDADE E PRODUÇÃO DE RESÍDUOS: a face oculta do sistema do capital
}

\author{
Izabel Cristina Bruno Bacellar Zaneti* \\ Laís Mourão Sá** \\ Valéria Gentil Almeida***
}

\begin{abstract}
Resumo: O artigo propõe uma reflexão sobre as condições estruturais que determinam o fenômeno dos sistemas de reciclagem de resíduos sólidos na sociedade contemporânea, com especial ênfase no aspecto das relações de trabalho e na lógica da produção. Nesta perspectiva, examina-se a relação entre a produção de resíduos, o desequilíbrio ecológico e o estágio atual de desenvolvimento das forças produtivas, dentro da racionalidade do sistema de produção do capitalismo avançado, baseado na exacerbação do consumo e do descarte. Conclui-se que, na hipótese de um processo real de sustentabilidade, controlado pelo Estado - para além da regulação sociotécnica e econômica por um sistema de gestão integrada, desde a produção do lixo-resíduo-mercadoria, até a disposição final e a reintrodução do mesmo na cadeia produtiva - seria necessário contar com a disposição da gestão pública no sentido de implementar processos coletivos capazes de atuar sobre as dimensões cultural e educacional da sustentabilidade, alterando os padrões sociais de produção e consumo.
\end{abstract}

Palavras-chave: resíduos sólidos; relações de trabalho e lógica de produção; sustentabilidade; sombra do sistema do capital.

* Doutora em Desenvolvimento Sustentável pela Universidade de Brasília (UnB), professora visitante no Centro de Desenvolvimento Sustentável da UnB. E-mail: izaneti@terra. com.br

** Doutora em Antropologia pela Universidade de Brasília (UnB), professora da Faculdade de Educação e do Centro de Desenvolvimento Sustentável da UnB.E-mail: laís.maria@terra. com.br

*** Doutoranda em Desenvolvimento Sustentável na Universidade de Brasília (UnB). E-mail: valeriagentil@uol.com.br

Artigo recebido em 6 out. 2008 e aprovado em 15 fev. 2009 
Isto aqui é um depósito dos restos. Às vezes são restos, às vezes vem também descuido. Resto e descuido. (...) Miséria não, mas regras sim. Economizar as coisas. As pessoas têm que prestar atenção ao que elas usam. (...) Eu sinto orgulho e tristeza, eles usam espaços e sujam tudo.

(Estamira, referindo-se ao Aterro Sanitário Jardim de Gramacho, 2006. $)^{1}$

\section{Introdução}

As necessidades humanas não são nem ilimitadas, nem biologicamente fixadas, mas constantemente redimensionadas e condicionadas socialmente de acordo com as potencialidades e determinações produtivas do intercâmbio metabólico estabelecido com a natureza. O capitalismo avança por meio de uma crescente subordinação das necessidades socialmente determinadas pelo mercado. Isto se efetiva pelo antagonismo permanente entre a constante reconversão dos meios de produção em capital e a satisfação social das necessidades humanas.

O presente artigo tem por objetivo refletir sobre as condições estruturais que determinam o fenômeno dos sistemas de reciclagem de resíduos sólidos na sociedade contemporânea, com especial ênfase no aspecto das relações de trabalho e na lógica da produção. Nesta perspectiva, examina-se a relação entre a produção de resíduos, o desequilíbrio ecológico e o estágio atual de desenvolvimento das forças produtivas, dentro da racionalidade do sistema de produção do capitalismo avançado, baseado na exacerbação do consumo e do descarte.

Mészáros (2002) aponta que, até o século XIX, a prática da maximização da vida útil das mercadorias permitia e incentivava uma espécie de reutilização de materiais e instrumentos produtivos. A mudança na relação entre produção e consumo começou a acontecer depois da Segunda Guerra Mundial, em fins da década de 40 do século $\mathrm{XX}$, quando passou a predominar o interesse de 
expansão do complexo militar-industrial, tendo como consequência a subutilização institucionalizada tanto de forças produtivas quanto de produtos e a crescente dissipação ou destruição dos resultados da superprodução, por meio da redefinição prática da relação oferta/ demanda no próprio processo produtivo.

À medida que aumenta a competição por preços mais baixos, passa a ocorrer na produção capitalista uma tendência geral de evitar a durabilidade. Os avanços produtivos são preferencialmente direcionados para os produtos de consumo rápido e para a produção generalizada do desperdício (Mészáros, 2002, p. 635). Esta tendência é justificada pela teoria econômica como função da necessidade de competição e da utilização racional dos recursos do trabalho. Os avanços na produtividade, que alteram o padrão de consumo e a utilização dos bens e dos instrumentos que os produzem, são considerados a priori bons e desejáveis. Por outro lado, as suas implicações negativas são vistas como inevitáveis, consideradas como intrínsecas ao desenvolvimento do capital. Nesta perspectiva, as contradições não aparecem como tal, mas sim como contingências momentâneas, no curso do desenvolvimento técnicocientífico e gerencial-organizacional. A lógica da reprodução do capital, enquanto princípio-eixo do paradigma que sustenta o próprio sistema, não pode ser questionada e reina soberana.

\section{Desperdício e entropia}

O equilíbrio entre produção e consumo, necessário para a reprodução do sistema produtivo, é alcançado por meio da geração de um consumo artificial, e em grande velocidade, de imensas quantidades de mercadorias, descartando-se prematuramente os bens consumidos. Até mesmo a aquisição dos chamados bens de consumo duráveis é manipulada no sentido de que sejam descartados muito antes de esgotada a sua vida útil. A tendência a favor do consumo 
imediato, denominada "tendência da taxa decrescente de utilização", é considerada na teoria econômica como uma característica intrínseca do avanço produtivo. Neste sistema de idéias, não se considera que o desperdício dos recursos naturais e do trabalho humano estão sujeitos à lei da entropia, derivada do segundo princípio da termodinâmica, nem se dá atenção ao fato de que, na dimensão planetária, o tempo biológico subordina o tempo humano (cf. Tiezzi, 1988, p. 32).

$\mathrm{Na}$ definição da relação entre valor de uso e valor de troca, o capitalismo precisa avançar para além dos limites da produção orientada para o valor de uso, já que este último acarretaria limites específicos à produção. Mészáros (2002, p. 643) aponta que, embora a legitimação do luxo circunscrito à classe abastada tenha tido um papel importante na expansão da produção capitalista, desde o século XVIII esta questão passa a ser relativizada. A partir de então, passaram a ser enfatizadas práticas produtivas orientadas para a expansão da quantidade e variedade de mercadorias consumíveis individualmente num mercado de massas, valorizando-se o consumo supérfluo como benéfico. A multiplicação da riqueza torna-se o objetivo da produção.

Como este tipo de desenvolvimento apresenta uma tendência para a produção em massa, por meio do avanço da divisão do trabalho e da técnica, impõe-se a necessidade de ir além do consumo limitado dos ricos. Assim, a tendência inicial é de que os trabalhadores também sejam incluídos no rol dos consumidores. No entanto, como já apontara Marx, o desenvolvimento histórico desigual e antagônico do sistema do capital apresenta, entre as suas contradições básicas, intrínsecas à própria natureza do sistema, a oscilação entre tendências e contra-tendências. Essas oscilações se manifestam entre polaridades como: monopólio versus concorrência; centralização versus fragmentação; internacionalização versus particularismos nacionais e regionais; equilíbrio versus desequilíbrio; e taxa de utilização crescente versus decrescente. Apesar da oscilação entre os pólos, um deles sempre tende a se tornar historicamente dominante, 
ou seja: o monopólio, a centralização, a internacionalização, o desequilíbrio e a lei tendencial da taxa de utilização decrescente.

Ao analisar a questão do desperdício, Mészáros examina especialmente a dominância da tendência à taxa de utilização decrescente, pela qual os resíduos de capital social total considerados ineficientes são abandonados por se tornarem não-lucrativos e inúteis, sendo vistos como supérfluos pelo capital. Nas dimensões da produção e do consumo, considerando-se o desenvolvimento do sistema nas últimas décadas, os efeitos negativos da taxa de utilização decrescente manifestam-se como desemprego, superprodução e subutilização de mercadorias, e uso perdulário da maquinaria produtiva. O encurtamento deliberado da vida útil das mercadorias possibilita o lançamento de um contínuo suprimento de mercadorias super-produzidas no vórtice da circulação que se acelera.

Em relação aos serviços e aos bens de consumo duráveis, produzidos em massa, há uma tendência à substituição, abandono ou aniquilamento deles. Trata-se da chamada obsolescência planejada, que se manifesta, por exemplo, na priorização do automóvel particular, em relação ao transporte coletivo, e na eliminação de habilidades e serviços de manutenção para compelir à compra dispendiosa de produtos ou componentes novos, quando os objetos descartados poderiam ser facilmente consertados. Quanto às instalações e máquinas, ocorre o sucateamento de maquinário novo após uso reduzido ou substituição por outro mais novo, tendência estimulada pela ideologia da inovação tecnológica, patrocinada pelo Estado mediante fundos para a pesquisa direta e básica e para instalações de corporações multinacionais.

\section{Trabalho vivo excluído e inclusão perversa}

A necessidade do capital de ter consumidores de massa leva ao investimento em altos salários, como tendência do mercado de 
trabalho. A inclusão provisória da classe trabalhadora no rol dos consumidores foi seguida historicamente pelos efeitos perversos da concentração mundial do capital, associada aos avanços tecnológicos poupadores de força de trabalho. Por volta da década de 70 do século passado, acentuam-se em ritmo crescente os fenômenos do desemprego e da exclusão social, tendência que vem se tornando historicamente dominante no atual estágio do desenvolvimento capitalista. A questão do desperdício dos bens materiais (naturais e fabricados) vem, então, historicamente acompanhada da descartabilidade da força de trabalho.

No que se refere ao desperdício da força de trabalho, cada vez mais rejeitada para fora do processo produtivo, Antunes (2005) alerta, no entanto, que isso não significa uma perda de centralidade do trabalho na sociedade contemporânea. Ele aponta a necessidade de se diferenciar o trabalho abstrato (dispêndio de energia física e/ ou intelectual) de sua dimensão concreta, como "elemento estruturante do intercâmbio social entre os homens e a natureza" (Antunes, 2005, p. 33). Para ele, considerando-se a lógica econômica que produz mercadorias pela valorização do capital, o que ocorre é uma redução do trabalho vivo e uma ampliação do trabalho morto, além de uma rearticulação na relação entre as dimensões intelectual e manual no trabalho abstrato.

Por outro lado, como coloca Mészáros (2002, p. 674), à medida que uma proporção crescente de trabalho vivo se torna trabalho supérfluo do ponto de vista do capital, a única saída, do ponto de vista dos trabalhadores, para atender às necessidades sociais e não desperdiçar o trabalho vivo socialmente disponível, seria um sistema não-concorrencial administrado no sentido da adoção e utilização criativa do tempo disponível, recuperando a unidade entre necessidade e produção. Embora isso seja inaceitável pela lógica de valorização e auto-reprodução expansiva do capital, a questão ajuda 
a jogar mais luz sobre os processos de inclusão/exclusão relativos à categoria de trabalhadores denominada "catadores".

Refletindo a partir de Marx sobre a relação complexa entre inclusão e exclusão, Mance (2002) comenta que o trabalho vivo excluído do sistema permanece parcialmente externo ao capital. Ele pode, por um lado, ser re-apropriado como fonte de sua própria superação sistêmica, mas também como possibilidade de emancipação da classe trabalhadora, na hipótese da emergência de um novo sistema produtivo.

Citando Enrique Dussel, o autor comenta essa alteridade do trabalho vivo em relação ao capital como um "outro radical", intrínseco à subjetividade e à atividade do trabalhador. Neste sentido, o tempo de "não-trabalho" do desemprego pode ser visto também como "tempo disponível" para inaugurar um outro tipo de relação de produção.

Quanto à noção de exclusão, o trabalhador, embora excluído da relação assalariada, está potencialmente incluído como consumidor. Nas alternativas individuais e/ou coletivas, pode ou não adotar e contribuir para a reprodução do sistema do capital, ou para a sua própria emancipação. Mance (2002) inclui no segundo caso as redes de consumo solidário. Da mesma forma, para o autor, a noção de inclusão não se esgota na mera idéia de reinserir os excluídos, mas implica

subverter a própria lógica do emprego de tecnologia em função de maximizar os lucros sob o capitalismo, (...) o que exigiria tanto a redução da jornada de trabalho que amplia o tempo livre, quanto o compartilhamento social da riqueza produzida (Mance, 2002, p. 3).

Boaventura de Souza Santos (2003) é outro autor que tem discutido amplamente a questão do protagonismo dos movimentos sociais, colocando entre as prioridades de suas lutas a questão da 
democracia e das reivindicações pela redistribuição social. A sua reflexão direciona-se para a tensão entre o capitalismo e a democracia, sublinhando o quanto a redistribuição é hostil ao capitalismo e como o capitalismo nunca redistribuiu voluntariamente. Foi necessária a luta dura do movimento operário e de outros movimentos sociais para conseguir o que até agora foi alcançado em termos de distribuição. Referindo-se às possibilidades de colaboração entre democracias representativas e democracias participativas, Santos menciona especialmente a sua articulação com sistemas alternativos de produção segundo uma lógica não-capitalista, como no caso dos movimentos cooperativos e de organizações econômicas populares que associam dimensões culturais e políticas à econômica.

Porém, examinando mais de perto o caso das populações urbanas que sobrevivem com base nos resíduos sólidos gerados pela cidade, pode-se afirmar, em princípio, que o trabalho vivo descartado retorna ao sistema sob as formas de trabalhadores residuais - os catadores - e de consumidores primários de resíduos.

Por um lado, poder-se-ia dizer que estes trabalhadores/ consumidores dispõem de forma autônoma do seu tempo de nãotrabalho, transformando-o em tempo livre. Dentre a diversidade de alternativas que essa autonomia manifesta, destacam-se os casos de categorias de catadores de resíduos sólidos urbanos que, em contraste com os migrantes definitivamente expulsos do campo, articulam várias fontes de sobrevivência em uma mesma unidade de reprodução familiar-parental, como é o caso de um grupo descrito na pesquisa de Bursztyn e Araújo (1997), entre os catadores de Brasília, citado adiante. O caso dos catadores é especialmente instigante por indicar que, ao largo da relação estritamente capitalista entre capital e trabalho (má-inclusão), e para além da radical condição de marginalidade (exclusão), grupos sociais dinâmicos estão construindo as suas alternativas de sobrevivência, nas brechas do rolo compressor do sistema dominante. 


\section{Catadores de lixo à sombra do sistema}

Segundo Zaneti (2006), a modernidade re-significa o lixo em resíduos sólidos enquanto valor de mercado. No entanto, os trabalhadores que vivem da coleta do lixo permanecem à sombra do sistema. Com efeito, Eigenheer (2008) comenta, nesta mesma direção, que a inclusão ou não de catadores em um sistema de limpeza urbana não é sinal de sua eficácia, pelo simples fato de que, para o sistema produtivo, o acesso a materiais que permitam a reciclagem de matéria-prima é muito mais importante do que a implantação de sistemas de limpeza urbana adequados.

Zaneti (2006) questiona, então, como pensar na gestão de um problema que lida com estes extremos: de um lado a riqueza, o consumo, o desperdício e o descarte e, de outro, a miséria, a inclusão perversa no sistema através dos catadores que juntam os restos nas casas e nas ruas? Estes catadores também têm a sua própria organização e dentro desta categoria também ocorrem várias gradações da sombra. A sombra social se manifesta, assim, como má inclusão, má participação, má existência. No entanto, ela existe, está presente e pulsa. Não está na escuridão completa (não-existência), nem está completamente iluminada (existência plena).

Buarque (1997), referindo-se aos catadores de lixo de Brasília, qualifica-os como "modernômades", que andam pelas cidades em busca de trabalho e de alimento, sobrevivendo do que encontram no lixo e da venda de resíduos. Nesse sentido, Gentil (2008) denomina esses trabalhadores como 'pessoas residuais', que são alvo da exploração tanto por parte do poder público, por meio da cobrança de impostos, taxas ou contribuições, quanto dos empresários, que exploram seu trabalho na tarefa de coleta e separação do resíduo útil às suas empresas.

Bursztyn (2002), ${ }^{2}$ nos estudos que desenvolve sobre o tema, nos diz que a primeira imagem que teve quando começou a estudar 
os catadores de lixo é que eles eram excluídos pela sua própria condição de vida. Porém, ao examinar a cadeia produtiva do lixo, percebeu que eles não podem ser definidos como excluídos, porque se incluem na ponta extremamente precária da cadeia produtiva dos resíduos, embora o seu modo de vida seja excluído. O catador é peça importante na cadeia produtiva do circuito industrial: por exemplo, o catador de latinhas faz parte da primeira etapa de um circuito que termina numa empresa multinacional de alumínio. Portanto, ele é mal incluído, porque trabalha na mais precária situação, porque o processo de catar e coletar este material é insalubre e irregular, sob o ponto de vista da legislação trabalhista, e injusto sob o ponto de vista das condições de vida. Bursztyn considera que o catador é socialmente excluído, enquanto trabalhador, mas tem um elo de pertencimento, portanto, de inclusão.

$\mathrm{Na}$ pesquisa de campo de Bursztyn e Araújo (1997) na cidade de Brasília, aparece uma nova categoria de migrantes. Ela é composta por jovens casais com filhos, em busca de melhorar as suas condições de sobrevivência, embora sem se desenraizar de seus locais de origem, rurais ou semi-urbanos, com os quais continuam mantendo fortes vínculos culturais e de parentesco. Essas famílias circulam entre o seu local de origem, onde residem de fato, e Brasília, em diversas rodadas, trabalhando como catadores de papel e de outros materiais recicláveis.

Brasília é muito atraente por causa dos resíduos gerados por órgãos públicos, principalmente, papéis, atraindo grande número de catadores e intermediários para a catação. O Decreto $n^{0}$ 5.940/06, assinado pelo presidente Lula sobre a coleta seletiva solidária, prevê no art. 1 ${ }^{\circ}$ : “A separação dos resíduos recicláveis descartados pelos órgãos e entidades da administração pública federal direta e indireta, na fonte geradora e a sua destinação às associações e cooperativas dos catadores de materiais recicláveis". 
Desta forma, os catadores no DF cadastrados na Central das Cooperativas (Centcoop) podem realizar a coleta dos resíduos regularmente nos órgãos federais e comercializar diretamente com as empresas recicladoras, eliminando em parte, os intermediários. Em 2007, cada cooperativa filiada à Centcoop recebeu como doação um triciclo motorizado (para pôr fim ao uso de carroças puxadas a cavalo na Esplanada dos Ministérios) com capacidade de armazenar até uma tonelada de resíduos. No entanto, as cooperativas dependem de incentivos para manutenção dos carrinhos e para abastecê-los.

Em 2008, o número de catadores no DF era, em média, de oito mil, provenientes do nordeste do Brasil. Embora incluam a atividade de catação num rol maior de estratégias de sobrevivência, os catadores entram no sistema hegemônico em uma relação de ultraexploração e quase marginal, ficando com a menor remuneração da cadeia de transformação do resíduo em matéria-prima.

Neste sentido, desvela-se a contra-tendência capitalista da taxa de utilização crescente da força de trabalho pela via da marginalidade, da mesma forma como, por exemplo, o capital agrário faz uso da escravidão nos empreendimentos de ponta das modernas fronteiras agrícolas ligadas às cadeias de produção de "commodities" (em especial a cana-de- açúcar/biocombustível).

Por outro lado, se considerarmos o caso dos catadores organizados em movimentos, associações e cooperativas, a relação de forças se equilibra um pouco mais, embora se crie uma total dependência do Estado. Essas organizações passam a atuar como mediadoras junto ao poder público para a arregimentação de trabalhadores na organização de alternativas de gerenciamento dos resíduos sólidos urbanos (cf. Belini et al., 2004). Submetidos a condições precárias e insalubres, esses trabalhadores abastecem as redes intermediárias de comercialização que contribuem para a realização dos lucros. Estão integrados em uma cadeia de produção 
que começa neles, passa pelas empresas intermediárias nos serviços de reciclagem e chega finalmente às grandes empresas compradoras de matérias-primas recicladas, de alto valor econômico.

Segundo Gentil (2008), o processo de comercialização dos resíduos no DF apresenta um determinado grau de complexidade, incluindo a diferença entre os chamados intermediários e atravessadores, bem como o que é considerado trabalho formal e informal. As empresas que compram os resíduos, ocupando o topo da pirâmide, encontram-se na ponta final da cadeia de comercialização e exportam para as indústrias recicladoras localizadas em outras regiões do país. O trabalho formal é aquele desenvolvido por funcionários das empresas que comercializam materiais recicláveis e reaproveitáveis (intermediários). Já o trabalho informal é realizado por catadores, atravessadores e sucateiros. Os catadores, embora desempenhem um papel fundamental na cadeia produtiva, representam o elo mais frágil de todo o sistema.

\section{A sustentabilidade na insustentabilidade?}

Como vimos, o funcionamento do sistema capitalista atual tende a apagar na prática a distinção entre consumo e destruição, em decorrência da sua contradição intrínseca entre valor de uso e valor de troca. A lógica do sistema do capital não tem como meta a produção em si, mas sim a sua auto-reprodução como capital, em oposição aos interesses da produção humanamente significativa e compensadora. Dessa maneira, podemos ver claramente como o uso da noção de desenvolvimento sustentável, sem qualquer esforço crítico quanto à lógica do sistema do capital, se constitui, pura e simplesmente, numa afirmação inconsequente das práticas produtivas deste sistema.

É lamentável que a maioria dos autores que adotam a ótica da sustentabilidade não perceba a contradição entre os termos 
"desenvolvimento" e "sustentabilidade" nem o sentido profundo da insustentabilidade intrínseca do sistema do capital. Como destaca Tiezzi (1988, p. 32), o tempo tecnológico ou econômico do sistema do capital (tempo-dinheiro) é inversamente proporcional ao tempo biológico. Ao medir o progresso pela velocidade com que produz, o sistema do capital não tem possibilidade de sobreviver, é só uma questão de tempo real à disposição de nossa espécie no planeta Terra. Digamos, contudo, que não queremos, enquanto humanidade, abdicar de nossa capacidade lógica e criadora. Então podemos, pelo menos, pensar em soluções parcialmente sustentáveis, para um sistema de gestão de resíduos orquestrado pelo poder público.

Associar distribuição de renda justa com crescimento econômico não é uma tarefa banal em uma sociedade na qual a lógica capitalista é hegemônica. De acordo com Sachs (2002), o crescimento econômico se faz necessário, mas deve ser socialmente receptivo e implementado por métodos favoráveis ao meio ambiente, ao invés de favorecer a incorporação predatória do capital da natureza ao PIB. Portanto, é essencial uma distribuição diferente de propriedade e renda, mesmo em condições de crescimento acelerado. Como colocam as teorias sobre a questão da sustentabilidade, especialmente na versão clássica de Ignacy Sachs, e a partir das conclusões do estudo de Zaneti (2006), é indispensável a articulação entre as dimensões político-institucional, técnico-ecológica, socioeconômico-ambiental e cultural-educacional, para que os efeitos finais da insustentabilidade sejam, pelo menos, adiados.

Podemos perguntar, por exemplo: quais são as propostas e reivindicações alternativas colocadas pelos fóruns e organizações coletivas dos catadores, tais como as cooperativas, o Movimento Nacional de Catadores de Recicláveis, e os Fóruns Lixo e Cidadania? Algumas de suas propostas incluem a regulamentação legal de sua profissão, o investimento público em programas de capacitação dos catadores (para estruturação de cooperativas 
autônomas e para viabilizar a aquisição de veículos e equipamentos) e a cessão de áreas públicas para instalação das unidades de triagem de recicláveis. Outras entidades, como o Instituto Polis - Estudo, Formação e Assessoria em Políticas Sociais, e a Associação Brasileira de Engenharia Sanitária e Ambiental, colocam que o enfrentamento deste desafio passa por instituir uma política nacional que regulamente as responsabilidades das empresas geradoras de resíduos, no setor da indústria, do comércio e de serviços. Neste sentido, está em tramitação na Câmara dos Deputados o Projeto de Lei $n^{\circ}$ 203/91, que capitaneia contribuições de deputados com cerca de 140 projetos de lei mais uma proposta formal do Poder Executivo e outras contribuições do mesmo poder. Sob a coordenação de um GT constituído pela Câmara dos Deputados, há um relatório em preparação que contempla esse conjunto de contribuições, com vistas à aprovação de lei que institua a Política Nacional de Resíduos Sólidos (PNRS).

No entanto, um sintoma evidente do caráter insustentável do sistema do capital é o fato de que as questões de responsabilidade pós-consumo, instrumentos para análise de ciclo de vida dos produtos, para redução, reutilização, reciclagem e rotulagem, ou seja, propostas que responsabilizam a classe empresarial, têm encontrado grandes dificuldades para a sua operacionalização. Os fóruns e redes têm colocado também a sua grande preocupação com o fato de que, quando contemplam os interesses do setor privado, as propostas não resolvem devidamente a integração dos catadores no sistema de retorno pós-consumo, desconhecendo o papel dos catadores no re-encaminhamento dos materiais recicláveis ao mercado produtor. Outro aspecto escamoteado nas propostas do setor empresarial é o tipo de impacto que as empresas provocam tanto no meio ambiente quanto no orçamento público para a destinação dos resíduos industriais (Instituto Polis, 2006)

Alguns setores do empresariado chegam mesmo a minimizar irresponsavelmente a sua participação nos impactos sociais causados 
pelos resíduos industriais. O argumento em favor de sua nãoresponsabilização parte da pressuposição de que a produção destes resíduos pelas empresas é indispensável à qualidade de vida coletiva e concorda que eles devam ser tratados de modo ambientalmente sustentável. O argumento conclui então que, à medida que os resíduos servem como matéria reaproveitada pelos catadores, já não podem mais ser considerados "resíduos", e sim "matérias-primas", produtos que circulam no mercado. Portanto, neste argumento, o empresário não poderia ser "penalizado" (isto é, responsabilizado socialmente) por algo de que outros também se beneficiam (Grimberg et al, 2005). É escandalosamente nítida nesta argumentação a contradição entre o interesse privado e o coletivo, na lógica do sistema do capital. Estas são, provavelmente, algumas das razões pelas quais até hoje a Política Nacional de Resíduos Sólidos não foi aprovada.

Uma possibilidade, portanto, é pensar no papel do Estado no sentido da integração entre as diversas dimensões da sustentabilidade propostas por Sachs (2002), como fator de eficácia do sistema de gestão. Do ponto de vista técnico, a integração implica em consolidar a legislação e organizar a engrenagem da coleta e a disposição final para os diferentes tipos de resíduos em forma de cadeia, na qual cada elo tem um papel fundamental para o sucesso de todo o sistema. Ao fazer a gestão do processo, o poder público deveria atuar, a partir de uma visão macro, nas diferentes dimensões da sustentabilidade, ou seja, nas dimensões socioeconômico-ambiental, culturaleducacional e político-institucional. Dessa forma, ele pode fazer a gestão integrada dos diferentes projetos de coleta, das unidades de triagem e da disposição final, desde a remediação dos lixões até a construção e manutenção dos aterros sanitários.

O viés predominantemente econômico que interliga os diferentes atores acaba por produzir o efeito perverso de estimular a produção de lixo porque, para este conjunto de atores (empresas, intermediários, catadores e operadores de triagem), quanto mais 
lixo melhor, já que uma maior quantidade aumenta a perspectiva de lucro. Essa realidade estabelece conflitos com a dimensão ambiental e político-institucional, porque, quanto mais lixo houver, mais problemas existirão para se fazer a gestão e mais poluentes serão depositados no meio ambiente, haja vista a condição citada de finitude dos aterros (Zaneti, 2006).

Dessa maneira, numa visão utópica, seria necessário reverter a lógica do capital, impedindo que o interesse privado prevalecesse em detrimento do coletivo, no sistema público de gestão. O papel do Estado seria então o de fortalecer o caráter social e ambiental do processo. Isso não se refere apenas a questões técnicas e operacionais, mas também a questões sociopolíticas ligadas a mudanças nos paradigmas de produção e consumo assumidos na sociedade.

No verdadeiro sentido da sustentabilidade, seria necessário que o Estado, além de fazer a gestão integrada do resultado, ou seja, do lixo - resíduo - mercadoria, desde a sua produção até a disposição final e a sua re-introdução na cadeia produtiva, conduzisse a gestão pública no sentido de alterar os padrões de produção e consumo, atuando sobre a dimensão cultural e educacional da sustentabilidade, a qual é determinante dos comportamentos socioeconômicos dos atores em relação aos resíduos.

\section{A título de conclusão}

Ao discutirmos a questão da insustentabilidade como a face oculta do sistema do capital, associada à produção de resíduos, estamos enfatizando a idéia de que só pode existir proposta de sustentabilidade a partir da negação dos fundamentos da lógica do capital. Como foi visto, os princípios paradigmáticos que organizam esta lógica não suportam a superação do desperdício e da entropia, já que estes alimentam a sua própria reprodução. Por outro lado, ao tratar 
das possibilidades da sustentabilidade dentro desta insustentabilidade fundamental, trouxemos a questão da gestão pública democrática, como uma instância a partir da qual seria possível (segundo alguns autores, como Sachs, 2002) associar a justa distribuição de renda ao crescimento econômico.

No entanto, a própria compreensão sobre a lógica do capital, trazida a partir de Mészáros (2002), permite pensar que a contradição que se manifesta no nível da gestão pública é decorrente do fato de que, apesar de ser o Estado neoliberal instrumento direto dos interesses do capital, ele é, simultaneamente, espaço de disputa entre as diversas forças sociais implicadas na gestão pública. No caso da gestão dos resíduos, consideramos aqui os movimentos sociais e organizações de catadores como sujeitos coletivos implicados nesta disputa. Neste sentido, a tentativa de pensar a sustentabilidade no fundamento insustentável do capital só pode resultar em conclusões necessariamente contraditórias e utópicas, já que lidam com a contradição básica da luta de classes no sistema do capital.

A partir de Boaventura de Souza Santos (2003), a dimensão da gestão pública democrática foi considerada neste estudo enquanto espaço de explicitação política das contradições do sistema do capital, tendo em vista que este contém em si mesmo a impossibilidade radical da distribuição justa da riqueza. Neste sentido, a tensão entre capitalismo e democracia se manifesta como uma das dimensões inerentes às lutas sociais nos regimes políticos das democracias burguesas. $\mathrm{O}$ grande risco da classe trabalhadora é tornar-se dependente do Estado e deixar de vê-lo como um dos espaços privilegiados da luta social nessas democracias.

\section{Notas}

1 Estamira, filme de Marcos Prado (2006), vencedor de 25 prêmios nacionais e internacionais nos principais festivais de cinema, levanta 
questões como o destino do lixo produzido. Estamira vive em função da sua missão: revelar e cobrar a verdade dos homens. Do lixo da civilização, ela supera a sua condição de miserável e coloca em questão valores fundamentais, muitas vezes esquecidos pela sociedade.

2 Entrevista com Marcel Bursztyn, realizada em Brasília, novembro de 2002 (Zaneti, 2006).

Unsustainability and waste production: the hidden face of the capital system

\begin{abstract}
This study examines the structural conditions that determine the phenomenon of solid waste recycling systems in contemporary society, focusing largely on work relations and on the logic of production. From this perspective, it analyses the relation among waste production, ecological imbalance and the current stage of the development of production forces within the production system of advanced capitalism, which is based on the exacerbation of consumption and waste disposal. It was found that, in the hypothesis of a real process of sustainability, controlled by the State (apart from the socio-technical and economic regulation by an integrated management system, from the production of garbage-waste-supply until its final disposal and reintroduction in the productive chain), it would be necessary to have effective public management aiming at implementing collective processes that would act upon the cultural and educational dimensions of sustainability, changing thus the social patterns of production and consumption.
\end{abstract}

Key words: solid waste; work relations and logic of production; sustainability; shadow financial system.

\title{
Referências
}

ANTUNES, Ricardo. O caracol e sua concha: ensaios sobre a nova morfologia do trabalho. São Paulo: Boitempo, 2005.

BELINI, L.; NASCIMENTO, N.; MELO, G. Geração de trabalho, renda e o desafio ambiental na gestão dos resíduos sólidos no município de 
S. Paulo. Disponível em: <http://www.poli.usp.br/p/augusto.neiva/ nesol/Publicações/>. Acessado em: 10 nov.2004.

BUARQUE, Cristovam. A diáspora da modernidade (Prefácio). In: BURSZTYN, Marcel; ARAÚJO, Carlos H. Da utopia à exclusão: vivendo nas ruas em Brasília. Rio de Janeiro: Garamond; Brasília: Codeplan, 1997.

BURSZTYN, Marcel (Org.) No meio da rua: nômades, excluídos e viradores. Rio de Janeiro: Garamond, 2000.

BURSZTYN, Marcel; ARAÚJO, Carlos H. Da utopia à exclusão: vivendo nas ruas em Brasília. Rio de Janeiro: Garamond; Brasília: Codeplan, 1997.

EINGEHEER, Emílio M. Resíduos sólidos como tema de educação ambiental. Disponível em: <http://www.rst.org.br/artigos/residuossolidos-como-tema-de-educacao-ambiental $>$. Acessado em: $10 \mathrm{fev}$. 2008.

GENTIL, Valéria Almeida. Pessoas residuais e os resíduos das pessoas: uma análise do desenvolvimento mercadológico do Distrito Federal. 2008. Dissertação (Mestrado em Desenvolvimento Sustentável) - Universidade de Brasília, 2008.

GRIMBERG, E.; PIRES, J.; CAMPANI, A. Informe sobre o Encontro Nacional de Resíduos Sólidos e a Responsabilidade Pós-Consumo [ apresentado no] Fórum Social Mundial. São Paulo: Instituto Polis, 2005.

INSTITUTO POLIS. Documento final do Encontro Nacional Construindo Políticas Públicas para a Recuperação e Reciclagem de Resíduos Sólidos com Inclusão dos Catadores. Belo Horizonte, 2006.

MANCE, Euclides A. Exclusão e inclusão. Curitiba: Instituto de Filosofia da Libertação, 2002.

MÉSZÁROS, István. Para além do capital. São Paulo: Boitempo, 2002.

SACHS, Ignacy. Caminhos para o desenvolvimento sustentável. Rio de Janeiro: Garamond, 2002. 
192 Izabel Cristina B. B. Zaneti / Laís Mourão Sá / Valéria Gentil Almeida

SANTOS, Boaventura de S.; AVRITZER, Leonardo. Para ampliar o cânone democrático, In: SANTOS, B. S. (Org.). Democratizar a democracia: caminhos da democracia participativa. Rio de Janeiro: Civilização Brasileira, 2003, p. 39-82.

TIEZZI, Enzo. Tempos históricos, tempos biológicos: a Terra ou a morte, problemas da nova ecologia. São Paulo: Nobel, 1988.

ZANETI, Izabel Cristina B. B. As sobras da modernidade. Porto Alegre, RS: Corag, 2006. 